Asian J. Med. Biol. Res. 2021, 7 (3), 284-291; doi: 10.3329/ajmbr.v7i3.56138

\author{
Asian Journal of \\ Medical and Biological Research \\ ISSN 2411-4472 (Print) 2412-5571 (Online) \\ www.ebupress.com/journal/ajmbr
}

\title{
Article \\ Use of smartphones among first year MBBS students during COVID19 pandemic in Dhaka, Bangladesh
}

\author{
Sujan Saha ${ }^{1 *}$ and Samiha Bushra Nova ${ }^{2}$ \\ ${ }^{1}$ Department of Physiology, Sir Salimullah Medical College, Dhaka, Bangladesh \\ ${ }^{2}$ Sir Salimullah Medical College, Dhaka, Bangladesh \\ "Corresponding Author: Dr. Sujan Saha, Department of Physiology, Sir Salimullah Medical College, Dhaka, \\ Bangladesh. Phone: +8801790330016; E-mail: dr.sujansaha84@gmail.com
}

Received: 24 August 2021/Accepted: 27 September 2021/ Published: 30 September 2021

\begin{abstract}
Coronavirus disease (COVID-19) is an infectious disease caused by the SARS-CoV-2 virus. Most people infected with the virus will experience mild to moderate respiratory illness and recover without requiring special treatment. However, some will become seriously ill and require medical attention. The virus after first identification on December 2019 in Wuhan, China spreads very fast all over the world including Bangladesh. To reduce the risk of COVID-19 transmission among medical students, teachers and staff, Ministry of Health and Family Welfare of Bangladesh government implemented home quarantine on first year MBBS students of 202021 session and ordered to begin online classes. A cross-sectional study was designed to assess the usage of smart phone in each positive and negative ways among students. Randomly 196 students completed an internet form (mean age $19 \pm 2$ years). The questionnaire contains socio-economic, academic, quarantine connected data and smartphone usage. The majority of the participants (41.33\%) assured that the usage of smartphone has been multiplied to eight to 12 hours per day. Many demographic and quarantine factors are assessed e.g. students' gender, the sector of study additionally to the situation of quarantine (urban, rural) and also the speed of internet speed there showed statistically important associations with smartphone addiction throughout the quarantine. Smartphones are both a curse and a boon to the newer generation as a great way of getting used for education and entertainment purposes, conjointly influences a lot of sick habits within the first year MBBS students like looking adult sites or being obsessed on social or other websites. This study shows the use of smart phone in by the first year medical students of Sir Salimullah Medical College, Dhaka, Bangladesh in both positive and negative ways that also reflects the other first year medical students of 2020-21 session in Bangladesh.
\end{abstract}

Keywords: COVID19; M-learning; Smartphone addiction

\section{Introduction}

The pandemic of coronavirus disease of 2019 (known as COVID-19) is considered as a potential threat to public health that gained global attention after the 2003 Severe Acute Respiratory Syndrome (SARS) (WHO, 2003) followed by 2012 Middle East Respiratory Syndrome (MERS) (WHO, 2013). Coronaviruses are zoonotic viruses that circulate amongst animals and spill over to humans from time to time and have been causing illness varies from asymptomatic illness to severe respiratory failure and shock (Chan et al., 2020; Chen et al., 2020; Yang et al., 2020). On 4 February 2020, the Director-General of WHO briefed the Secretary-General of the United Nations and requested a UN system-wide scale up to assist countries to prepare for and respond to COVID-19. On 11 February 2020, Following WHO best practices for naming of new human infectious diseases, WHO has named the disease COVID-19, short for "coronavirus disease 2019" (WHO, 2020a; 2020b). Since then, the infection spread to other regions of Asia, gradually reaching Europe, North America, South America, Africa and Oceania, rendering it a pandemic by March 2020 (Chan et al., 2020). The International Committee of Taxonomy of Viruses (ICTV) classified the novel virus as severe acute respiratory syndrome coronavirus 2 (SARS-CoV-2) (Gorbalenya et al., 2020). On January 30, the World Health Organization (WHO) categorized 
the 2019-nCoV virus as the sixth Public Health Emergency of International Concern (WHO Statement on the Second Meeting of the International Health Regulations, 2005) and announced COVID-19 as a global epidemic on March 11, 2020.

M-learning reflects remote teaching techniques for lecturers additionally as learning ways for medical students, as a result, it helps to search on web about anything at anytime from anywhere (El-Sofany and El-Haggar, 2020). It also may help the scholars to reduce the study gap that play an alternate learning methodology throughout COVID-19 Mobile learning (m-learning) has become a preferred learning system for education particularly in every country of the world because of its multi-functionality characteristic and effectiveness. Bangladesh already initiated a project on National ICT policy-2009 to make the country as a middle-income nation within the year 2021 by appliance of ICT based education from primary to tertiary level which can facilitate to accomplish the goal (Rahman, 2015). On the other side, the total number of mobile subscribers had reached 159.780 Million at the end of March 2019 (BTRC, 2019). Most of the students at the have a smartphone that they will simply use for his or her tutorial purpose each offline and online. When declaring COVID-19 as a pandemic disease, several countries as well as Bangladesh have taken initiative to shut their all medical schools to reduce the impact of the virus (World Health Organization, 2020). Bangladesh had closed all of the educational institutions including medical colleges from the eighteenth of March, 2020 that became a reason behind lessening the quality of education and additionally the student's future life (Usak et al., 2020). Thus for overcoming this situation, an innovative learning methodology became vital (Toquero, 2020) and M-learning started playing a crucial role for the mobile devices uses among the medical sector (Sönmez et al., 2018; Aubusson, et al., 2009). For the COVID-19 pandemic time, the education system of the globe has affected extremely. Several countries of the world have shut down their academic establishments to reduce the transmission of this virus that become the reason for several challenges. The situation isn't totally different for Bangladesh.

The 2020-21 session of first year MBBS students gave their public admission test on the second April of 2021 (dghs.gov.bd). Their categories started by online from the first August of constant year. Smartphone holds a lot of importance in everyday life. Mobile phone and net usage became universal among every age of people. Still smartphone usage has both pros and cons. There's very little proof supporting the claim that excessive smartphone use will cause or worsen health problems, however it's simple that it will have an effect on users in several ways, physical and mental.

Hence this study was planned in first year medical students of Sir Salimullah Medical College, Dhaka, Bangladesh to study the pattern, purpose and impact of smartphone usage and their experiences of online learning through smartphones.

\section{Materials and Methods}

\subsection{Data source and analysis}

On the second week of August'2021 a pre-questionnaire form was developed for testing among 15 (around $5 \%$ of study population) first year students from different medical colleges by choosing them randomly from an online platform. After their feedback necessary changes were done to the online questionnaire form. Responses to the online form were submitted by 205 1st year MBBS students at Sir Salimullah Medical College throughout the first ten days of August 2021. After improvement of the data by removing all duplications 196 distinctive participants who had absolutely completed the web questionnaire and took part voluntarily remained for analysis. There was no missing data as all the queries were mandatory. Participants might withdraw at any time by failing to answer any of the questions. Participants' ages ranged between 17 to 20 years, with a mean of $19 \pm 2$, students were 94 male (47.96\%) and 102 female $(52.04 \%)$. All were studying for the basic subjects of first year of MBBS from the beginning of their higher studies as their session started from the mid July of 2021 and undoubtedly it started by online teaching through smartphones because of the corona pandemic. All interviewed questions were checked for its completeness, correctness and internal consistency to exclude missing or inconsistent data. Data was checked, cleaned, coded and edited properly before analysis. The analytical plan of the study includes description of the study population by their sociodemographic characteristics first. Descriptive statistics including means, medians, standard deviations and ranges for continuous data and frequencies and proportion for categorical data were calculated. Data was presented in appropriate tables and graphs. For inferential statistics $\chi^{2}$-test was used. All the tests was two tailed and $\mathrm{p}<0.05$ was considered statistically significant. 
2.2. Smartphone usage

\subsubsection{Smartphone using in online learning, classes, entertainment purposes}

In addition to the addiction scale, the questionnaire included a couple of questions regarding the amount of hours spent using smartphones per day. Students were asked about their experiences of online classes, distractions and self-learning methods through the quarantine, and therefore the level of change in usage was assessed. Students were also asked about the foremost frequent smartphone applications (Facebook, YouTube, Twitter, Snapchat, Instagram, and Netflix) used before and through the quarantine.

\subsubsection{Smartphone addiction scale-short version}

Smartphone Addiction Scale (SAS) The SAS (Kown et al., 2013) is a 33-item self-report measure of behaviors associated with problematic smartphone use. The 33 items are arranged into six subscales: Daily-Life Disturbance, Positive Anticipation, Withdrawal, Cyberspace-Oriented Relationship, Overuse, and Tolerance. The 10 final questions were selected using content validity. The internal consistency and concurrent validity of SAS were verified with a Cronbach's alpha of 0.911 . The SAS-SV was significantly correlated with the SAS, SAPS and KS-scale. The SAS-SV scores of gender $(\mathrm{p}<.001)$ and self-evaluation of smartphone addiction $(\mathrm{p}<.001)$ showed significant difference.

\subsection{Ethical considerations}

The participants were informed in details about the nature of the study. They will not exposed to any physical, psychological and social risk. Only the individuals willing to participate in the study will be included. The responses have been remained confidential and are not unidentifiable. Given information are kept indefinitely in digital format and only used for the research purpose.

\section{Results}

The questionnaire formed by the web was randomly distributed among first year MBBS students of Sir Salimullah Medical College of Dhaka, Bangladesh through social networking sites where a big number of students took part during this online survey. Out of them, a total of 196 responses were found valid and selected for data analysis. By using software, the collected data were analyzed quantitatively. This section presents results of the study including basic information of respondents, also about frequency of using the web, time spending on smartphone each day, using smartphone for tutorial purpose or not, preference of social networking sites for learning, medical students' frequent use of social media applications, and MBBS students' perception and attitude about smartphone learning.

The original sample consisted of 205 submissions, which were then reduced to 196 after omitting duplicated responses. Total 94 male and 102 female students have participated in this survey. Their percentage is respectively $47.96 \%$ and $52.04 \%$. The survey shows that $137(69.90 \%)$ of the students lived in urban area whereas the percentage of living in rural area is much lower $(30.10 \%)$ and is decreased to 59 in number. The students living in urban area expressed much better internet speed than those living in rural areas. Students at their home got 'very strong' internet speed in only $2.94 \%$ cases (6). The rate increased much in case of 'strong' internet connection which resembles $30.39 \%$ (62) of the total students (196). The highest percentage is shown in case of 'moderate' net connection which is $49.02 \%$ (100). The rate again dropped to $15.69 \%(32)$ and $1.96 \%$ (4) when respectively asked about 'poor' and 'very poor' connection.

Since the first year MBBS students mostly used their smartphones for study purposes, many of them faced disturbances while operating their devices. 35.34\% (94) of them felt that poor signal of internet affects them the most, whereas the rate decreased a bit to $22.56 \%$ (60) where students expressed that load-shedding was the actual reason. The rate further decreased to $19.17 \%$ (51) in case of technical problems they faced with their devices. $8.65 \%$ (23) of them chose the option 'financial problem'. Only $14.29 \%$ (38) of the first year medical students of Sir Salimullah Medical College said that they hadn't faced any disturbances while operating their personal smartphones.

Three questions were asked to the students to know about their academic responses and experiences of online classes, exams in the pandemic. The first question of this series was whether they had faced any problems understanding the contexts of the classes and tutorials. Only $2.43 \%$ (8) of the responders felt that they understood the contexts most of the time where majority of the students chose difficulties while doing online classes. 13.98\% (46) of them chose 'One way communication' as the reason of not understanding medical studies. The percentage increased to $30.40 \%$ (100) when they chose 'Lack of practical knowledge' as a reason for not understanding the classes through smartphones. The rate of not getting the contexts further increased to $37.39 \%$ (123) when participants chose 'Too much information in a short period'. $15.81 \%$ (52) of the total 
responders accepted that they are 'simply not getting habituated' to the online classes. Second query of this series of questions was placed to know if the students store notes/slides/videos on their smartphones to use as resources while self-learning. $18.88 \%$ (37) of the students strongly agreed to this statement, $45.92 \%$ (90) agreed, $23.47 \%$ (46) remained neutral, $7.65 \%$ (15) disagreed and $4.08 \%$ (8) strongly disagreed to this. Third query was to know whether they use online resources (apps/websites/articles/journals) from smartphones to use for selflearning. Majority accepted that they use 'Youtube'as their resources. The rate of using youtube in students came $70.20 \%$ (172). Then $6.12 \%$ (15) expressed that they use 'various paid apps and websites'. 'Online courses on social sites' were used by $11.84 \%$ (29) of the participants. $8.57 \%$ (21) of the responders accepted that they use various articles/blogs/journals for self-learning. Only 3.27\% students expressed that they didn't use any online resources for self-studying.

One of the main purposes of this study was to find how smartphone distracted the first year medical students from their studies and other works. 33.55\% (104) of the responders accepted that they used to roam on apps or websites leaving the online classes on. $26.45 \%$ (82) of them used to operate other apps while self-studying also. 66 participants having the rate of $21.29 \%$ thought that they had already developed smartphone addiction. $12.90 \%$ (40) of the students expressed that they had become bored of using smartphones continuously on daily basis. Only $5.81 \%$ (18) of the participants said they didn't get distracted while using smartphones.

In case of developing smartphone addiction, $48.55 \%$ (117) of the participants showed their addiction towards social sites and gaming sites. $15.77 \%$ (38) 0 them showed addiction on movie and web series sites. $4.46 \%$ (11) of the first year MBBS students expressed addiction on adult sites and pornography. About $21.58 \%$ (52) claimed that they didn't develop any kind of smartphone addiction. This research shows an alarming rate of daily smart phone using duration of the participants. Only 9.18\% (18) of the students used smartphone less than five hours, $33.67 \%$ used it for around eight to twelve hours. Majority $(41.33 \%$ ) used smartphone for around $41.33 \%$. Students using their smartphone for twelve to sixteen hours showed percentage of $13.27 \%$ and the rate decreased to $2.55 \%$ in case of using for more than sixteen hours. A question was asked to know whether the smartphone usage by first year MBBS students of Sir Salimullah Medical College in the corona pandemic made them efficient and punctual than before. $3.57 \%$ (7) strongly agreed that smartphone made them more efficient, $10.20 \%$ (20) only agreed to this claim, $25.51 \%$ (50) remained neutral. But majority disagreed with this claim where the rate became $36.73 \%$ (72). A good number of participants, $23.98 \%$ (47) strongly disagreed to this.

A very important section of this study was to ask the students if the increased usage of smartphone hampering their physical and mental health. In case of physical problems, 28.86\% (101) assured that they were suffering from headache, $26.86 \%$ (94) accepted that they felt the loss of eye sight, 31.14\% (109) agreed to sleeping irregularities. Only $4.57 \%$ (16) refused that they faced any physical issues regarding the daily usage of smartphone for a longer period. After asking about physical issues, questions were asked to know the first year MBBS students' mental condition after experiencing one month of continuous exams and classes only through their smartphones. Only $8.33 \%$ (26) refused and assured they hadn't faced any yet till then. Whereas, $22.76 \%$ of the participants assured of cabin fever and depression for staying at home for a long period, $21.47 \%$ (71) agreed that they were facing shortness of temper. And the majority chose suffering from headache where the percentage reached to $41.99 \%$ with the involvement of 131 students.

The last query to the participants was how they were evaluating their online studies through their smartphones. It became a tie, $40.82 \%$ (80) in choosing 'Disagree' and 'Strongly disagree' when they were asked if the online study had just been the same like the traditional offline MBBS classes. Only $12.24 \%$ remained neutral to this claim, the percentage decreased more in choosing 'agree' and became only $3.57 \%$ (7), further decreased to $2.55 \%$ (5) where those participants 'strongly agreed' to the same quality of both offline and online classes in the pandemic.

This study showed significant correlation $(\mathrm{p}<0.001)$ between duration of smartphone use with development of addiction using Smartphone addiction scale (Table 1), also it this study showed significant correlation $(\mathrm{p}<0.005)$ (Table 2) between duration of mobile use with development of physical issues among the students, but there was no significant correlation ( $\mathrm{p}<0.001$ ) (Table 3) between development of mental issues with duration of smartphone use by the students. 
Table 1. Relation of development of smartphone addiction with usage of smartphone.

\begin{tabular}{|c|c|c|c|c|c|c|}
\hline Development of Addiction & Very short & Short & Long & Very long & Excessive & p value \\
\hline I haven't developed any yet & $9(50.0)$ & $25(37.9)$ & $16(19.8)$ & $1(3.8)$ & $0(0.0)$ & $<0.001$ \\
\hline Movie or web series sites & $0(0.0)$ & $2(3.0)$ & $6(7.4)$ & $3(11.5)$ & $0(0.0)$ & \\
\hline $\begin{array}{l}\text { Movie or web series sites | Adul } \\
\text { sites }\end{array}$ & $0(0.0)$ & $0(0.0)$ & $0(0.0)$ & $2(7.7)$ & $0(0.0)$ & \\
\hline Movie or web series sites | Others & $0(0.0)$ & $0(0.0)$ & $0(0.0)$ & $0(0.0)$ & $1(20.0)$ & \\
\hline Social sites and gaming sites & $4(22.2)$ & $31(47.0)$ & $36(44.4)$ & $11(42.3)$ & $1(20.0)$ & \\
\hline $\begin{array}{l}\text { Social sites and gaming sites | Adul } \\
\text { sites }\end{array}$ & $0(0.0)$ & $0(0.0)$ & $1(1.2)$ & $2(7.7)$ & $0(0.0)$ & \\
\hline $\begin{array}{l}\text { Social sites and gaming sites } \\
\text { Movie or web series sites }\end{array}$ & 2 (11.1) & $1(1.5)$ & $10(12.3)$ & $3(11.5)$ & $1(20.0)$ & \\
\hline $\begin{array}{l}\text { Social sites and gaming sites } \\
\text { Movie or web series sites | Adul } \\
\text { sites }\end{array}$ & $1(5.6)$ & $3(4.5)$ & $0(0.0)$ & $2(7.7)$ & $0(0.0)$ & \\
\hline $\begin{array}{l}\text { Social sites and gaming sites } \\
\text { Movie or web series sites | Others }\end{array}$ & $0(0.0)$ & $0(0.0)$ & $0(0.0)$ & $0(0.0)$ & $1(20.0)$ & \\
\hline $\begin{array}{l}\text { Social sites and gaming sites } \\
\text { Others }\end{array}$ & $0(0.0)$ & $1(1.5)$ & $4(4.9)$ & $1(3.8)$ & $1(20.0)$ & \\
\hline
\end{tabular}

Table 2. Relation of development of physical problems with usage of smartphone.

\begin{tabular}{|c|c|c|c|c|c|c|}
\hline Physical problems due to use of smartphone & Very short & Short & Long & Very long & Excessive & p value \\
\hline Headache & $1(5.6)$ & $10(15.2)$ & 11 (13.6) & $2(7.7)$ & $0(0.0)$ & $<0.005$ \\
\hline Headache | Loss of eye sight & $0(0.0)$ & $8(12.1)$ & $6(7.4)$ & $2(7.7)$ & $0(0.0)$ & \\
\hline Headache | Loss of eye sight $\mid$ Others & $0(0.0)$ & $1(1.5)$ & $0(0.0)$ & $2(7.7)$ & $0(0.0)$ & \\
\hline $\begin{array}{l}\text { Headache | Loss of eye sight | Sleep } \\
\text { irregularities }\end{array}$ & $3(16.7)$ & $8(12.1)$ & $11(13.6)$ & $6(23.1)$ & $1(20.0)$ & \\
\hline $\begin{array}{l}\text { Headache | Loss of eye sight | Sleep } \\
\text { irregularities | Others }\end{array}$ & $0(0.0)$ & $1(1.5)$ & $5(6.2)$ & $3(11.5)$ & $1(20.0)$ & \\
\hline Headache | Others & $0(0.0)$ & $0(0.0)$ & $1(1.2)$ & $0(0.0)$ & $0(0.0)$ & \\
\hline Headache | Sleep irregularities & $0(0.0)$ & $4(6.1)$ & $5(6.2)$ & $2(17.7)$ & $0(0.0)$ & \\
\hline Headache | Sleep irregularities | Others & $0(0.0)$ & $1(1.5)$ & $4(4.9)$ & $0(0.0)$ & $2(40.0)$ & \\
\hline I haven't faced any yet & $7(38.9)$ & $5(7.6)$ & $3(3.7)$ & $1(3.8)$ & $0(0.0)$ & \\
\hline Loss of eye sight & $1(5.6)$ & $12(18.2)$ & $6(7.4)$ & $1(3.8)$ & $0(0.0)$ & \\
\hline Loss of eye sight $\mid$ Others & $0(0.0)$ & $0(0.0)$ & $1(1.2)$ & $0(0.0)$ & $0(0.0)$ & \\
\hline Loss of eye sight $\mid$ Sleep irregularities & $1(5.6)$ & $2(3.0)$ & $9(11.1)$ & $2(7.7)$ & $0(0.0)$ & \\
\hline Loss of eye sight $\mid$ Sleep irregularities |Others & $0(0.0)$ & $0(0.0)$ & $1(1.2)$ & $0(0.0)$ & $0(0.0)$ & \\
\hline Others & $1(5.6)$ & $2(3.0)$ & $3(3.7)$ & $0(0.0)$ & $0(0.0)$ & \\
\hline Sleep irregularities & $4(22.2)$ & $12(18.2)$ & $15(18.5)$ & $4(15.4)$ & $1(20.0)$ & \\
\hline Sleep irregularities |Others & $0(0.0)$ & $0(0.0)$ & $0(0.0)$ & $1(3.8)$ & $0(0.0)$ & \\
\hline
\end{tabular}


Table 3. Relation of development of mental problems with usage of smartphone.

\begin{tabular}{|c|c|c|c|c|c|c|}
\hline Mental problems due to use of smartphone - & Very short & Short & Long & Very long & \multicolumn{2}{|c|}{ Excessive p value } \\
\hline Decreased attention & $7(38.9$ & $23(34.8)$ & $29(35.8)$ & $6(23.1)$ & $1(20.0)$ & 0.107 \\
\hline Decreased attention | Depression & $2(11.1)$ & $6(9.1)$ & $8(9.9)$ & $3(11.5)$ & $0(0.0)$ & \\
\hline Decreased attention | Depression | Others & $0(0.0)$ & $0(0.0)$ & $0(0.0)$ & $1(3.8)$ & $0(0.0)$ & \\
\hline Decreased attention | Others & $0(0.0)$ & $0(0.0)$ & $1(1.2)$ & $0(0.0)$ & $0(0.0)$ & \\
\hline Decreased attention | Shortness of temper & $0(0.0)$ & $3(4.5)$ & $8(9.9)$ & $2(7.7)$ & $1(20.0)$ & \\
\hline Decreased attention | Shortness of temper | & $0(0.0)$ & $5(7.6)$ & $8(9.9)$ & $5(19.2)$ & $1(20.0)$ & \\
\hline \multicolumn{7}{|l|}{ Depression } \\
\hline Decreased attention | Shortness of temper | & $0(0.0)$ & $0(0.0)$ & $6(7.4)$ & $1(3.8)$ & $1(20.0)$ & \\
\hline \multicolumn{7}{|l|}{ Depression | Others } \\
\hline Decreased attention | Shortness of temper $\mid$ & $0(0.0)$ & $1(1.5)$ & $2(2.5)$ & $0(0.0)$ & $0(0.0)$ & \\
\hline \multicolumn{7}{|l|}{ Others } \\
\hline Depression & $1(5.6)$ & $6(9.1)$ & $3(3.7)$ & $1(3.8)$ & $1(20.0)$ & \\
\hline Depression | Others & $0(0.0)$ & $1(1.5)$ & $0(0.0)$ & $0(0.0)$ & $0(0.0)$ & \\
\hline I haven't faced any yet & $7(38.9)$ & $13(19.7)$ & $5(6.2)$ & $1(3.8)$ & $0(0.0)$ & \\
\hline Others & $0(0.0)$ & $3(4.5)$ & $0(0.0)$ & $0(0.0)$ & $0(0.0)$ & \\
\hline Shortness of temper & $0(0.0)$ & $3(4.5)$ & $7(8.6)$ & $2(7.7)$ & $0(0.0)$ & \\
\hline Shortness of temper|Depression & $1(5.6)$ & $2(3.0)$ & $4(4.9)$ & $4(15.4)$ & $0(0.0)$ & \\
\hline
\end{tabular}

\section{Discussion}

The study was performed among the first year MBBS students in an urban medical college, where all participants had mobile phones \& most of them were using personal smartphones. This shows a different observation from students of public university both from home and abroad. A study where student from public university from Bangladesh participated (Biswas et al., 2020.) the daily usage of smartphone among public university students of Bangladesh shows much different information. In our study, the percentage of using phone below one hour is $8.2 \%$, this rate increased to $42.8 \%$ in case of using one to three hours, $30.3 \%$ used smartphone for four to five hours. Whereas in our study the percentage of using smartphone among first year medical students came $41.33 \%$ in case of using for eight to twelve hours every day which is much higher than the public university students and also alarming.

In case of public university students, mobile learning helps them to enhance their motivation in $56.8 \%$ where only $5.81 \%$ student in our study confirmed that they had never got distracted which is much lower rate and also doesn't show a good response to the online classes. In Maharastra, India a study shows that disturbance of sleep and headache happen sometimes respectively to $79 \%$ and $15.69 \%$ of their students. In our study the percentage of sleep disturbance and headache are $31.14 \%$ which is comparatively lower and $28.86 \%$ which is again higher (Yadav et al., 2020).

The rate of using facebook in the study 'Smartphone Use among University Students during COVID-19 Quarantine: An Ethical Trigger' is 39.6\% in this pandemic whereas in our study, the rate of addiction of facebook or other social sites among participants is $48.55 \%$ which is comparatively higher. The negative impact of smartphone in the study 'The Impact of University Students' Smartphone Use and Academic Performance in Bangladesh: A Quantitative Study' shows the rate 38.40\%. And in our study, only around 30\% student agreed that smartphone in this pandemic has made them more efficient and punctual. Both of these percentages are relatively nearer to each other. In the same study (Saadeh et al., 2021) the percentage of getting distracted because of smartphone shows $38.90 \%$. A much higher rate is shown in our study which is $94.19 \%$. This shows an alarming rate among the first year medical students of Sir Salimullah Medical College which also resembles the other students of 2020-21 session in Bangladesh. Such a negative use of smartphone among young generation can bring irreparable damage to the future of medical science in our country and to the outer world.

The chi square test shows the relation between the most important information of this study and those are the residences of the participants, network signal according to their residences and disturbances they face while operating their smartphones. Our study focuses on the overall effect on medical students of first year MBBS students. After seeing all the percentages and evaluating their answers, it is clearly seen that the majority of the 
students are definitely not happy with their pandemic experiences. If the topic is only about their studies, the gap of their knowledge has been highlighted the most. Selecting the options e.g. one way communication of online classes, mental pressure of understanding too much information in a short period, absence of practical knowledge by the majority doesn't show an effective result of online classes over smartphones. But using smartphones for their study resources and storing class and context related notes/slides showed a good rate among them. As web is an open source for all, this pandemic encouraged every student to explore this vast site of resources. Some apps such helped the students a lot to understand their contexts of studies. But the most negative side of their experiences is the worsening condition of their physical and mental health. Majority expressed headache, sleep irregularities, decreased attention, shortness of temper and depression as their health problems and also showed significant correlation between duration of use of smartphone and development of smartphone addiction which was also evident in previous stories (Alosaimi et al., 2016; Eldesokey et al., 2016 ). This study has several limitations. The study only included medical students from a single medical college and from students who just started their graduation journey, result may vary if senior students were added. Moreover the study was done in an urban medical college, situated in the capital city of the country. The result may vary if medical students from other district could be added. We may also have a biased selection of medical students who own smartphones. With a total of 196 responses, we believe that these results are likely to be generalizable to medical teaching institutions in Dhaka and surrounding cities. Though the study showed significant correlation between duration of smartphone use and physical health problems, but denied significant correlation with mental health problems; the result may change if the study would done in larger scale and suggests another study should be done in larger scale. The study also examined self-reported experiences. Participant responses were, therefore, subject to both recall bias and response bias. The study suggests that medical colleges should take care of their students and teach the students the smartphone etiquettes more to help them in using their personal smartphone more effectively. Undoubtedly, technology is closely related to medical science in this modern world. The better use of smartphones can give us a much better knowledge to understand medical science perfectly and it should get started from the first year of MBBS life.

\section{Conclusions}

Quarantine may be a nerve-racking situation with many challenges, casting its shadow over routine life. No previous study has assessed the connection between quarantine and smartphone addiction levels in first year MBBS students throughout the quarantine period. Feminine gender, urban areas, living accommodations quarantine, higher income, and scientific and medical majors had higher and important overuse scores. The SAS-SV scores are on top of antecedent rumored scores for alternative countries, though they're admired in other countries within the region. Whether or not an addiction or overuse, the high scores and prevalence reported are frightening and indicate the severity of smartphone dependence among First year of Sir Salimullah Medical College students during the quarantine. A repeat form on a comparable study population with follow-up interventions is warranted.

\section{Acknowledgements}

We like to thank the students (First Year) of Sir Salimullah Medical College who participated in the study and for their utmost support.

\section{Conflict of interest}

None to declare.

\section{Authors' contribution}

Sujan Saha: conceptualization, methodology, data collection and analysis supervision, manuscript writing, reviewing and editing.

Samiha Bushra Nova: methodology, data collection, data analysis, manuscript writing

\section{References}

Alosaimi FD, H Alyahya, H Alshahwan, N Al Mahyijari and SA Shaik, 2016. Smartphone addiction among university students in Riyadh, Saudi Arabia. Saudi Med. J., 37: 675-683.

AubussonP, S Schuck and KBurden, 2009. Mobile learning for teacher professional learning: benefits, obstacles and issues. ALT-J, 17:233-247.

Biswas B, SK Roy and F Roy2020. Students perception of Mobile learning during Covid-19 in Bangladesh: university student perspective. AQUADEMIA, 4: ep20023. 
BTRC, 2019. Mobile Phone Subscribers Bangladesh March 2019. Retrieved on 5 June 2020 http://www.btrc.gov.bd/content/mobile-phone-subscribers-bangladesh-march-2019

Chan JFW, S Yuan, KH Kok, KKW To, H Chu and Yang, J, 2020. A familial cluster of pneumonia associated with the 2019 novel coronavirus indicating person-to-person transmission: a study of a family cluster. The Lancet, 395: 514-523.

Chen N, M Zhou, X Dong, J Qu, F Gong and Y Han, 2020. Epidemiological and clinical characteristics of 99 cases of 2019 novel coronavirus pneumonia in Wuhan, China: a descriptive study. The Lancet, 395: 507-513.

Eldesokeya S, G Zeinab, S Yomna, AHL Gilanyc and E Mohamed, 2021. Smartphone addiction among medical students in mansoura university. https://www.researchgate.net/publication/350592223_Smartphone_ addiction_among_medical_students_in_mansoura_university

El-Sofany HF and N El-Haggar, 2020. The Effectiveness of Using Mobile Learning Techniques to Improve Learning Outcomes in Higher Education. International Journal of Interactive Mobile Technologies, 14: 4-18.

Gorbalenya AE, SC Baker, R Baric, RJD Groot, C Drosten and AA Gulyaeva, 2020. Severe acute respiratory syndrome-related coronavirus: The species and its viruses-a statement of the Coronavirus Study Group: 1-15

Kwon M, DJ Kim, H Cho and S Yang, 2013. The smartphone addiction scale: development and validation of a short version for adolescents. PLOS One, 8: 83558.

Rahman L, 2015. Digital Bangladesh: Dreams and Reality. The Daily Star. https://www.thedailystar.net/ supplements/24th-anniversary-the-daily-star-part-1/digitalbangladesh-dreams-and-reality-73118

Saadeh H, RQ Al Fayez, A Al Refaei, N Shewaikani, H Khawaldah, S Abu-Shanab and Maysa Al-Hussaini, 2021. Smartphone use among university students during COVID-19 quarantine: an ethical trigger. Front. Public Health, 9: 00134.

Sönmez A, I Göçmez, D Uygun and M Ataizi, 2018. A review of current studies of mobile learning. Journal of Educational Technology and Online Learning, 1: 12-27.

Toquero CM, 2020. Challenges and opportunities for higher education amid the COVID-19 pandemic: The Philippine context. Pedagogical Research, 5: em0063.

Usak M, AR Masalimova, EI Cherdymova and AR Shaidullina, 2020. New playmaker in science education: Covid-19. Journal of Baltic Science Education, 19: 180.

World Health Organization, 2020. Coronavirus disease 2019 (COVID-19): situation report.

Yadav JU and DJ Yadav, 2017. Study of mobile phone usage in medical students of deemed university of Western Maharashtra, India. Int. J. Community Med. Public Health, 4: 405-408.

Yang X, Y Yu, J Xu, H Shu, H Liu and Y Wu, 2020. Clinical course and outcomes of critically ill patients with SARS-CoV-2 pneumonia in Wuhan, China: a single-centered, retrospective, observational study. The Lancet Respiratory Medicine, 8: 475-481. 